\title{
Narrativas del vídeo viral. 99 claves para un contenido contagioso
}

\author{
Narratives of the viral video. 99 keys for a contagious content
}

\author{
Laura PICAZO SÁNCHEZ \\ Universidad Complutense de Madrid - España \\ laura.picazo.sanchez@gmail.com
}

Cómo citar este artículo: PICAZO SÁNCHEZ, Laura (2016): «Narrativas del vídeo viral. 99 claves para un contenido contagioso», Mediaciones Sociales, no 15, pp. 115-132. DOI: http://dx.doi.org/10.5209/MESO.54546

Recibido: 31 de octubre de 2016.

Aceptado: 24 de noviembre de 2016.

\section{RESUMEN}

Preocupados por conocer las características dramáticas y narrativas que tienen en común los vídeos que sufren un contagio a través de los medios y con el objetivo de poder clasificarlas y comprender así las claves de esta expansión masiva, tomamos como referencia una muestra de 1.000 vídeos de comportamiento viral. Examinamos el contenido de los mismos extrayendo 99 claves de contenido que concentran la atracción del espectador y desencadenan los procesos de contagio. Estas claves, convenientemente aplicadas al contenido videográfico, contribuyen al éxito y la difusión del mismo, pudiéndose alcanzar, en función de los parámetros aleatorios y de distribución, un proceso de contagio.

PALABRAS CLAVE: audiencia, contenidos, vídeo, viral, YouTube.

\section{ABSTRACT}

Concerned about the narrative features that viral videos have in common, it has been taken a sample of 1000 viral videos in order to classify them and understand the keys of their massive contagion in media. We examine their content, extracting 99 keys that concentrate the attraction of the viewer and trigger the spreading process. These keys, suitably applied to the video content, 
drive it to its success and its diffusion, being possible a contagion process, depending on the random and distribution parameters.

KEYWORDS: audience, contents, video, viral, YouTube.

Sumario: 1.Introducción. 2. Método y materiales. 3. Resultados. 3.1. Claves del contenido viral. 4. Conclusiones. Bibliografía.

\section{INTRODUCCIÓN}

El fenómeno de aportación de contenidos deviene en la actualidad comunicativa en una tendencia de consumo audiovisual marcada radicalmente por la participación del usuario (Burguess y Green, 2009). Éste, relegado antes a ser receptor y a un feedback muy limitado, aprovecha su oportunidad y se expresa según su criterio propio, construido en base a medios tradicionales - de los que lleva un siglo siendo receptor- y a sus propias inquietudes y experiencias (Snickars y Vonderau, 2009). El manejo del término viral va directamente unido a la proyección de la atención de los públicos (Teixeira, 2012) y a la búsqueda de un beneficio económico. Se trata de un tipo de éxito que impacta de forma masiva (Burguess, 2008) y cuyas repercusiones lucrativas han eclipsado la necesidad de una identificación y la falsa eficacia de copias. La importancia de un comportamiento de contagio aplicado a contenidos audiovisuales a tal nivel de consumo justifica una designación rigurosa y un criterio especializado en la identificación de sus procesos y la comprensión de los objetos a los que afecta (Teixeira, 2014). La investigación global del fenómeno viral del vídeo en YouTube tiene como objetivo responder a estas cuestiones y aplicar exactitud a las aproximaciones (Voltz y Grobe, 2013). De este estudio se deriva una vertiente que se preocupa del contenido viral y sus características dramático-narrativas, estableciendo la necesidad y oportunidad de conocer sus particularidades.

Abordar el contenido desde la perspectiva de la viralidad implica una severa observación del usuario y sus difusiones (Broxton et al., 2013). No existe un acuerdo científicamente respaldado sobre las características del comportamiento viral y sus contenidos, por lo que se impone establecer un diseño analítico aplicado a una muestra representativa de vídeos virales, y esgrimir de su examen las claves dramáticas de dichos elementos.

\section{MÉTODO Y MATERIALES}

El método de trabajo escogido para llevar a cabo esta investigación sobre el vídeo viral es el Análisis de contenido. Para fijar el objeto de estudio extraemos una mues- 
tra de 1.000 vídeos $^{1}$ que han sido escogidos a partir de vínculos textuales con el término viral en blogs ${ }^{2}$, webs de contenido y redes sociales ${ }^{3}$, medios de comunicación tradicionales ${ }^{4}$ y página de inicio de YouTube $e^{5}$ (especialmente Vídeos destacados).

La selección de los vídeos se ha regido por su presencia en YouTube: de cada elemento se extrae contenido audiovisual, link del vídeo en YouTube, título, número de visitas, nombre del canal emisor, fecha de emisión, estadísticas del vídeo, número total de comentarios del vídeo y transcripción de hasta 100 comentarios. Sin embargo, la falta de concreción definitoria del fenómeno viral y de los contenidos a los que se aplica este comportamiento complica la formación de la muestra, ante cuya construcción se nos plantea la necesidad de revisar y precisar rigurosamente los criterios de identificación viral (Pérez, 2011). Para ello se procede a una visualización del vídeo atendiendo a formato y contenido, esgrimiendo si pertenece o no el vídeo a una campaña de marketing. Cuando un vídeo es la obra más visitada de su canal, se recoge también la siguiente información adicional:

- Valoración del número de reproducciones correspondiente al target del vídeo ${ }^{6}$.

- Se indaga en Internet buscando precedentes del título y su autor atendiendo a los vídeos de su canal, las visitas de cada uno de ellos y las fechas en que han sido publicados.

- Descodificación del apartado Estadísticas del vídeo.

Aplicado este proceso, la muestra se reduce a 468 elementos videográficos de comportamiento viral, y todos han sido difundidos en YouTube entre junio de 2005 y mayo de 2013.

La investigación principal tiene como objeto extraer toda la información posible relacionada con el proceso viral de un vídeo, para lo que se diseña un extenso Proto-

${ }^{1}$ La extracción de la muestra se inicia el 22 de octubre de 2012 y finaliza el 13 de junio de 2013.

2 Confessions of an Aca-fan, Digital Buzz Blog, Blogs El País, Enrique Dans, Juan Sánchez Bonet, Social Steve, Viral blog, Viral viral videos.

3 Argyle Social / Viral Heat, BBC, Bussinesses Grow, Buzzfeed, El Huffington Post España, Ellen Degeneres Show, Eweek, Facebook, Google, Goviral, Inaglobal, Le Huffington Post France, Mashable, Menéame, NBC, New York Times, Oahoknacchnkn, Pinterest, Revista Newsweek, Reddit, Revista TIME, Social Media Examiner, Social Times, TED, The Guardian, The Huffington Post US, The Huffington Post UK, Todo Viral, Tuenti, Tumblr, Vine, Washington Post, YouTube, Antena 3 en YouTube, Buzzfeed en YouTube, Ellen en YouTube.

4 El País, El Mundo, ABC, RNE, Cadena SER, Onda Cero TVE1, La 2, Antena 3, TeleCinco, La Sexta, Cuatro.

${ }^{5}$ Este acceso a la plataforma se realiza sin registro de usuario.

${ }^{6}$ Para establecer el nivel de audiencia de una pieza, debe aplicarse una estimación que tenga en cuenta las características del contenido difundido, el tipo de difusor (nombre del usuario, canal) y ámbito de influencia, intención de la pieza (o público asequible en función del contenido, formato, título, descripción o frame mediante el que se presenta) y comparación con el resto de piezas difundidas por el usuario. 
colo de análisis de más de 400 parámetros desarrollados en base a los bloques de Contenido, Forma, Difusión y Recepción. Para alcanzar los objetivos de clasificación y caracterización de contenidos virales, podremos hacer uso de los resultados que se desprenden de los bloques Contenido y Formato ${ }^{7}$, representados en el gráfico 1 . Sin embargo, se desprende de la aplicación del protocolo a la muestra la existencia de numerosos atributos de los vídeos que no están siendo procesados por no formar parte de los enunciados del protocolo elaborado. Para ello, y con el fin de poder reflejar y procesar correcta y representativamente las características del contenido viral, se decide proceder a un análisis extra, aislado del resto de visionados que forman la estructura metodológica de la investigación, y a lo largo del cual el analista extraiga el factor más llamativo de la narrativa dramática del vídeo. Se extraen así las llamadas Claves del contenido del vídeo, aspectos que comprenden desde el título y frame con que la obra es representada en YouTube hasta cualquier aspecto de su composición narrativa o formal que pueda considerarse el elemento más atractivo del vídeo.

7 Se trata de parámetros sobre la acción y sus características, su contexto y sus circunstancias, los requisitos de su ejecución, el modo, fin, objeto e instrumento de la acción, su ejecutor y su beneficiario así como las características de dichos agentes, el desarrollo y construcción del relato, su formato y grabación, el idioma, el tono y la temática del vídeo. 
Gráfico 1. Registro de claves dramáticas en la muestra de vídeos analizada

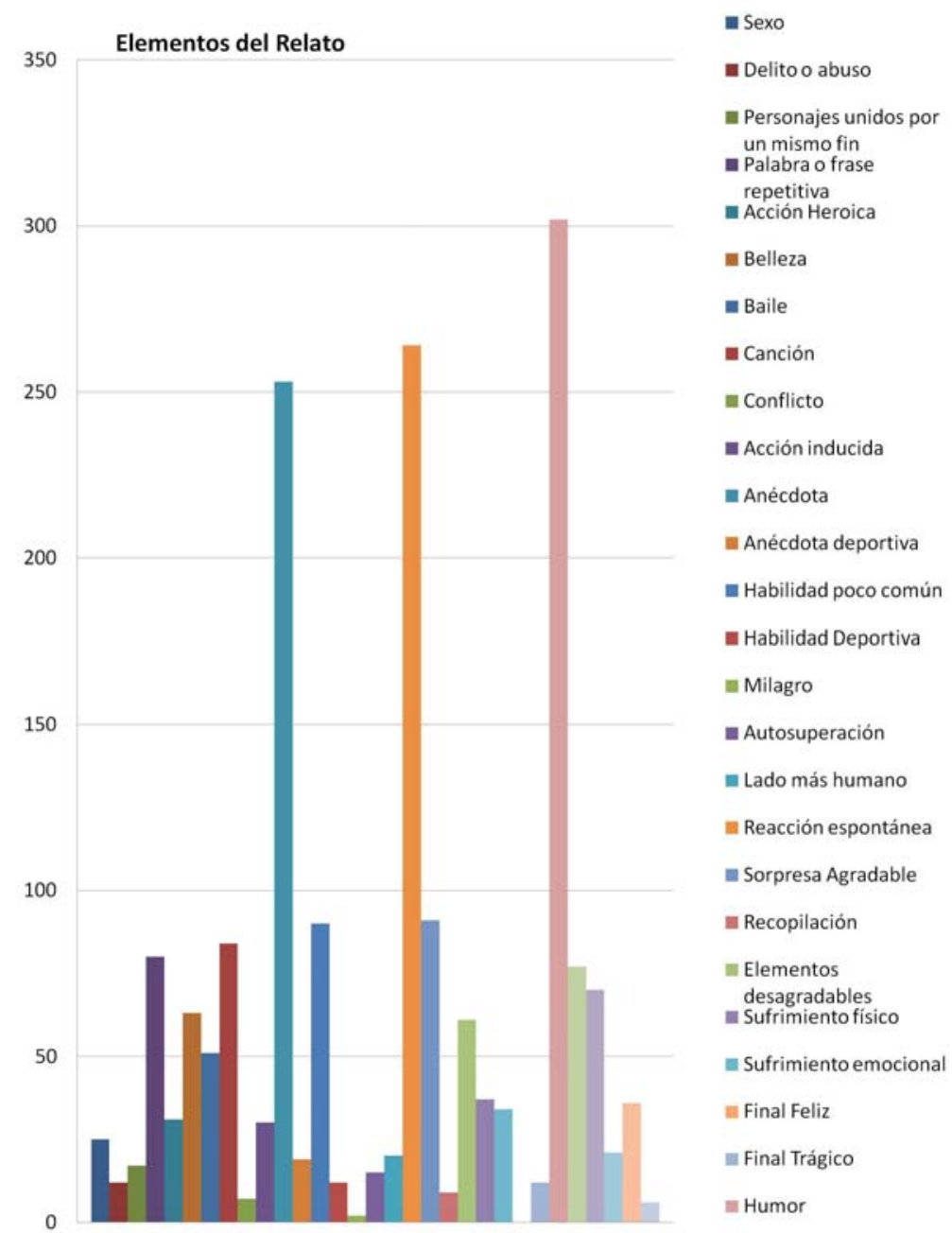

Fuente: Autora.

\section{RESULTADOS}

\subsection{Claves del contenido viral}

Concluido el visionado completo de la muestra y extraídas dichas claves, son procesadas para establecer una frecuencia de las mismas. Los resultados se han organizado en función de parámetros concretos de la narración, que dan lugar a los siguientes grupos de Claves del contenido: 
- En función del riesgo que entraña la acción y de la finalidad de la misma:

1) Acción heroica. Consiste en una actividad realizada por un agente de forma voluntaria y por medio de cuya ejecución librará de un peligro a otro agente más débil.

- En función de la oportunidad para realizar la acción del vídeo:

2) Acción in fraganti ${ }^{8}$. De realización oculta o misteriosa, se trata de una acción que es descubierta por otro agente para sorpresa de éste. También se denomina así al contenido de una grabación clandestina que se revela en exclusiva a su espectador.

3) Acción irrepetible captada en cámara. Se corresponde con la oportunidad de grabar el momento preciso en el lugar adecuado. El valor de este gancho reside en la naturalidad con que converge el acto de grabar con un acontecimiento que, además, resulta genuino e irrepetible.

\section{- En función de la realidad:}

4) Acción captada de la realidad. Estas acciones carecen de edición de vídeo, montaje o posproducción. El carácter realista de la grabación constituye una repetida clave de contenido en los vídeos de comportamiento viral. Se entiende también como captación en vivo (no televisiva).

5) Acción alterada o fingida mediante montaje. Pese a que las acciones reales en captaciones reales se configuren como claves de contenido, el carácter fantástico, evocador o la ilusión de inverosimilitud que puede generarse gracias al montaje se erige como un perfil de atractivo en los vídeos de comportamiento viral.

\section{- En función de la casualidad:}

6) Acción casual. La casualidad se define como una combinación de circunstancias que no se pueden prever ni evitar.

7) Accidente. Se extrae de la experiencia con la muestra que los accidentes ${ }^{9}$ conforman un núcleo dramático de atracción.

8 La muestra revela que las acciones in fraganti son grabadas con cámara oculta, cámara de seguridad o cámara de visión nocturna.

9 Suceso eventual o acción que involuntariamente resulta daño para las personas o las cosas. 
- En función de la intención:

8) Acción intencionada. El carácter intencionado de la acción, que permite diferenciar acciones con un fin o un objetivo de aquellas sin propósito explícito, se perfila como gancho.

\section{- En función de la previsión:}

9) Acción previsible. El carácter previsible de la acción, que se advierte en contenidos con una trama de desarrollo lógico y que otorga al espectador las claves para que éste proponga un desenlace y participe activamente del vídeo.

10) Relato imprevisible. El caso opuesto al anterior es la trama imprevisible, cuyo desarrollo no puede predecir o atisbar el espectador, lo que puede acentuar el nivel de atracción por parte de éste, así como disminuir su participación.

\section{- En función de la premeditación con que se desencadena la escena:}

11) Broma o burla que es descubierta por su víctima. Acorde con la acción in fraganti, especifica la actuación en la burla que un agente le practica a otro sin que éste se dé cuenta, pero que acaba descubriendo con el desarrollo del relato. En estos contenidos, el espectador es testigo y conocedor de toda la acción.

12) Broma de cámara oculta. En estos casos, la víctima de la broma padece un engaño guiado por un personaje conocedor del fin burlón de los hechos. El desarrollo de los acontecimientos es filmado, aspecto que también ignora la víctima y que descubre al final.

\section{- En función de la dualidad acción/reacción:}

13) Susto. La acción consiste en una sorpresa ejecutada por un personaje a otro con el fin de generar una impresión negativa en éste.

14) Sorpresa. Acción imprevisible para un personaje $A$ y que es ejercida por un personaje $B$ con el fin de generar una impresión positiva en aquel.

15) Reacción natural y/o espontánea. La acción referida como reacción natural o espontánea es improvisada por un agente ante un estímulo provocador.

16) Gesto inconsciente. Reacción involuntaria e inevitable vinculada a una expresión física ejecutada por un agente en un estado de pérdida del conocimiento y por ello la capacidad de percibir y darse cuenta de lo que le rodea, por ejemplo, durante el sueño o sedación. La reacción por sí sola no supone un gancho, sino que suele entenderse como gancho acompañada del personaje que la interpreta. 
- En función del carácter extraordinario de la acción que se lleva a cabo:

17) Habilidad. Capacidad y disposición poco frecuentes ejecutadas por personajes en el desarrollo de la grabación constituyen un ámbito de atractivo de contenido que se clasifica como gancho.

18) Habilidad deportiva. Dentro del grupo anterior, las habilidades deportivas concentran la mayoría de acciones de este tipo registradas en la muestra. Conforman por sí solas claves de contenido.

19) Proeza deportiva. Hazaña o valentía, la proeza deportiva está conceptuada entre la habilidad deportiva y la acción heroica, pues consiste en la ejecución de una acción ordinaria o extraordinaria que adquiere el cariz de proeza por la situación en que se lleva a cabo o las características de su ejecución, aspectos en los que radica su atractivo como gancho de contenido del vídeo.

20) Milagro. Basado en un fenómeno sobrenatural, la acción milagrosa es aquella que surge o acontece de forma inexplicable y que acarrea consecuencias positivas.

21) Testimonio narrado de forma excéntrica. La clave de esta acción consiste en la forma en que un hecho, relato o cualquier tipo de mensaje es contado, independientemente del contenido del mismo. Normalmente, el testimonio se considera excéntrico por las cualidades de su emisor.

22) Revelación pública. Se entiende como el mensaje polémico, sorprendente o impropio que uno o varios personajes comparten con otros, y cuya puesta en común es captada en el vídeo.

\section{- En función de temáticas de aprendizaje:}

23) Demostración de una utilidad. En el vídeo se lleva a cabo una exhibición explicativa del uso o la fabricación de un objeto.

24) Experimento en vivo. Estas piezas recogen una experiencia que entraña algún riesgo (aunque éste sea de poca transcendencia). El atractivo de estos vídeos reside en el desconocimiento del desenlace o resultado de dicha actividad.

25) Descubrimiento extraordinario. Consiste en una experiencia genuina para el agente protagonista captada en el momento en que éste la vive. Conlleva un conocimiento o descubrimiento de carácter único o extraordinario que el espectador tiene la sensación de descubrir a la vez que su protagonista. 
- En función de los límites de la legalidad y el morbo:

26) Desafío o reto (a la autoridad). Actividad de riesgo y éxito improbable que el protagonista presenta u ofrece al espectador en el vídeo. Un desenlace favorable al agente ejecutor otorga un mayor atractivo al contenido. En el caso de consistir en un desafío a la autoridad, el atractivo reside en el riesgo o peligro existente en el acto mismo del reto, independientemente del resultado.

27) Polémica. La polémica constituye un relato atractivo por el carácter morboso del enfrentamiento, la controversia o el cruce de los límites de la corrección, el protocolo, etc.

28) Delito. La captación de un delito y/o su castigo constituye un contenido atractivo. Está vinculado a acciones in fraganti.

29) Sufrimiento físico. El morbo como atractivo abarca la captación de imágenes que relaten el sufrimiento humano físico y psicológico y el sufrimiento físico animal.

- En función de la atención:

30) Apelación. Acto o llamada de atención directa que el vídeo emite hacia el espectador.

- En función de contenidos con canción y baile:

31) Flashmob ${ }^{10}$.

32) Lipdub ${ }^{11}$.

- En función del tipo de grabación:

33) Directo televisivo.

34) Spot sobre la advertencia de un peligro público. Grabación de edición profesional, con montaje y posproducción que emite un mensaje persuasivo acerca del abandono de una conducta o un consumo concreto.

\footnotetext{
${ }^{10}$ Su traducción literal es "multitud instantánea", y consiste en una acción organizada en la que un gran grupo de personas se reúne en un lugar público y, de forma aparentemente repentina, realiza algo inusual y luego se dispersa rápidamente. Suelen convocarse a través de redes sociales y la mayor parte de los casos no tienen más fin que el entretenimiento.

11 Se trata de un vídeo musical en que el/los protagonistas sincronizan sus labios con la letra de una canción (playback) generando una versión de vídeo de la misma. Se realizan en una sola toma (plano secuencia) y suele tratarse de un hit musical.
} 
35) Programa o concurso de televisión. Contenido basado en el extracto de un programa o concurso de televisión en cuyo desarrollo tiene lugar una acción o actividad que se corresponde con alguna de las claves del vídeo.

36) Cámara oculta. Grabación de cámara oculta.

\section{- En función de la circunstancia:}

37) Situación de peligro mientras se graba. La grabación tiene como objeto una actividad u objeto concretos pero la circunstancia de la misma es de peligro, y ésta también se refleja en el vídeo, resultando el aspecto de mayor atractivo de la pieza.

\section{- En función del gancho temático:}

38) Cute. Consiste en el contenido basado en la actividad -sea cual fuere- que ejecutan humanos y animales de corta edad o cuyas características físicas o psicológicas convierten en impropias o dificultosas ciertas acciones, generando en todo caso situaciones de ternura.

39) Touching ${ }^{12}$. Se denomina así al contenido de carácter sentimental o emotivo, que describe una situación emocionante. Se incluyen dentro de este gancho la acción touching y el relato touching, registrados en la muestra.

40) Funny. Contenido consistente en una acción divertida o graciosa, cuyo reclamo reside en el humor o la diversión.

41) Private. Escena perteneciente a la vida íntima de uno o varios personajes, que no suele compartirse y a la que no se tiene acceso en condiciones de normalidad.

42) Wild ${ }^{13}$ (time lapse). Relato de un hecho, objeto o circunstancia de una forma en que, normalmente, no es posible presenciarlo.

43) Jackass $^{14}$. Contenido basado en una actividad realizada voluntariamente por el protagonista y que acarrea una consecuencia de dolor físico para el mismo.

44) Top Secret ${ }^{15}$. Relato extraordinario sobre una circunstancia que podría calificarse de wild o private, con la característica de que alude a temas legales,

\footnotetext{
12 Puede ser agradable o desagradable.

${ }^{13}$ Se opta por el término wild (salvaje) por reflejar una representación de la realidad genuina, natural o hiperrealista.

14 Jackass fue un programa de televisión iniciado en el año 2000 cuyo contenido estaba basado en actividades divertidas que un grupo de jóvenes realiza para infringirse dolor.

${ }^{15}$ Alusión a temas legales, gubernamentales, normalmente ajenos al ciudadano corriente.
} 
gubernamentales o legislativos, relacionados con la justicia y la seguridad de un sistema político y sus ciudadanos, y que reflejan una situación de peligro para su protagonista en estos ámbitos.

45) Happy. Vídeo consistente en un relato de tono agradable y simpático, normalmente emisor de una circunstancia feliz o el deseo de la misma.

46) Respuesta viral. Numerosa y continua (durante el disparo viral) proliferación de copias y versiones amateur que los espectadores y usuarios de YouTube publican en la red. No se trata de un grupo de versiones anecdóticas aisladas sino que se consolida como una tendencia de creaciones que complementan el comportamiento viral que padece la pieza ${ }^{16}$.

47) Man on the moon ${ }^{17}$. Hecho extraordinario en la historia de la humanidad cuya grabación y emisión es orquestada a nivel mundial y emitida de forma masiva en múltiples medios de comunicación ${ }^{18}$.

- En función de la falta de propiedad entre elementos de la narración:

48) La acción es impropia a la naturaleza del personaje que la lleva a cabo, de la circunstancia en que se realiza o del lugar en que se ejecuta. Dentro de este gancho encontraríamos el tipo: Habilidad impropia a personaje.

49) El personaje que ejecuta la acción es impropio a la naturaleza de la misma, de su circunstancia o del lugar en que la realiza.

50) La circunstancia en que se ejecuta la acción es impropia a la naturaleza del personaje, de la acción o del lugar en que se realiza.

51) El objeto con el que se ejecuta la acción es impropio a la naturaleza de la misma, del personaje que la lleva a cabo, de la circunstancia o del lugar en que se realiza.

52) El modo en que se ejecuta la acción es impropio a la naturaleza del personaje, de la acción, del objeto participante, de la circunstancia o del lugar en que se realiza.

53) El elemento es impropio a la realidad o a la vida real. Uno de los aspectos compositivos de la narración o el relato difiere de la realidad o de la vida real, generando una situación de falta de propiedad con respecto del resto de elementos (reales) del relato. Esa inverosimilitud resulta, como los casos an-

\footnotetext{
16 Uno de los casos de respuesta viral más famosos es Harlem shake (Ruismäki y Ruokonen, 2013).

17 Toma su nombre del Patrón del comportamiento viral Man on the moon.

${ }^{18}$ Un ejemplo es el vídeo La caída de Félix Baumgartner desde la estratosfera.
} 
teriormente descritos, de elevado atractivo a merced de los resultados de la experiencia.

54) Spot con mensaje contradictorio. Correspondiente también a la carencia de propiedad entre dos elementos, resulta especialmente llamativo el uso de una marca en una pieza de carácter promocional en la que el mensaje es, precisamente, disuasorio del consumo del producto al que se refiere.

\section{- En función de las consecuencias de la edición:}

55) Recreación de escena inverosímil. La generación de una situación en la que coexisten elementos impropios entre sí conseguidos mediante el montaje o edición de la imagen o el sonido que conforman un conjunto surrealista o inverosímil, ya sea por su falta de fidelidad a la realidad o el desajuste entre características de varios de los elementos de la pieza.

56) Inducción a la acción mediante música editada. La adición de música o sonido por medio de herramientas de montaje y posproducción da al relato un sentido diferente del que aporta la imagen por sí sola, creando la ilusión de una connotación o mensaje diferente, en ocasiones inverosímil y divertido.

57) Falta de propiedad entre acción, circunstancia y personaje. El efecto de la edición del contenido refleja una disociación entre tres elementos de fuerte peso en el relato: acción, circunstancia y personaje no convergen de forma narrativamente lógica unos con otros, recreando una sensación de inverosimilitud que hace atractivo el contenido en su conjunto.

58) Simulación por montaje a cámara rápida. Inscrito en la categoría de Wild, se identifica como la demostración de una acción duradera en un corto espacio de tiempo. En condiciones temporales normales el vídeo sería considerablemente más largo y nunca podríamos verlo de esta manera si no es porque la grabación ha sido alterada, o no se podría extraer la información y mensaje que proporciona como podemos hacerlo a cámara rápida. La brevedad constituye en sí una de las características que facilitan que un contenido extenso pueda consumirse y compartirse adquiriendo una difusión viral.

\section{- En función de las características del personaje:}

59) Personaje indefenso (animal o niño). En consonancia con su condición de corta edad o ignorancia, el niño se presenta como un personaje habitualmente indefenso que es, en sí mismo, un reclamo de contenido, sobre todo en acciones heroicas. El animal es un personaje transmisor de esta imagen de indefensión y también conforma un reclamo de contenido. 
60) Niño / Niño con sobrepeso perceptible. Por sus atributos físicos y la naturaleza de su condición, el niño resulta un atractivo de contenido. El trabajo con la muestra establece una tendencia hacia el niño con exceso de peso como reclamo de atracción.

61) Celebrity. La aparición de un personaje conocido o celebrity aporta un atractivo cuya trascendencia varía en función del tipo de personaje y de la audiencia potencial que pueda sentirse atraída por el mismo.

62) Protagonista anónimo. El personaje cualquiera representa al espectador del vídeo. Puede desempeñar un factor clave de atracción, ya que resulta altamente efectivo en la identificación con la audiencia. Influirán el nivel de protagonismo que se le otorgue y la acción que desarrolle, así como la posición o rol que adquiere al término del relato.

63) Animal. El registro de un animal es, a merced de los resultados del estudio, una clave de contenido en vídeos de comportamiento viral. De la aplicación del Protocolo de análisis a la muestra se extrae que estos animales son, en su mayoría, domésticos ${ }^{19}$.

64) Personaje cruel. La crueldad como atributo a un personaje, otorgado en virtud de la acción que realiza en el vídeo, se ha registrado como un parámetro de notable frecuencia y, por tanto, se clasifica como gancho de contenido, asociado a su personaje.

65) Con talento. Característica asociada al personaje que demuestra en el vídeo poseer un genio distintivo o virtud que le permiten destacar en algún ámbito. Se incluirán también en este grupo a los personajes con aptitudes o características sobresalientes.

66) Cute. De significado tierno, se aplica a cualquier personaje que despierte ternura. Se trata de una característica inherente al personaje, pero puede registrarse en una acción cuyo ejercicio es propio del personaje cute.

67) Llamativo. Característica identificativa que se aprecia en un personaje. Constituye un parámetro de atracción en sí y, como tal, un gancho de contenido registrado en la muestra.

68) Elocuente. Característica del personaje que emite su discurso de forma fluida y expresiva. Se registra con frecuencia entre las claves de atención del contenido de comportamiento viral, según el estudio de la muestra.

\footnotetext{
${ }^{19}$ Se registran perros en primer orden de frecuencia y gatos en segundo.
} 
69) Inocente (víctima de broma, susto). Acorde con el gancho Personaje indefenso, la víctima de una broma o susto constituye un gancho de contenido que se confirma imprescindible en los relatos de este tipo.

70) Antihéroe. El concepto de antihéroe se registra en los contenidos de comportamiento viral como el de personaje anónimo. Supone el gancho de un considerable número de vídeos examinados en la muestra.

71) Carismático. La experiencia confirma que el personaje carismático, que fascina o atrae por sí mismo, constituye como tal un gancho de contenido, incluso independientemente del resto de elementos que componen el relato.

72) Personajes desconocidos entre sí que forman parte de una misma acción con fines positivos. La unión de desconocidos (aparentemente) con fines altruistas constituye un relato repetido en la muestra y concentra el núcleo de atención de los relatos en que aparece.

\section{- Por definición de la escena:}

73) Desagradable. La muestra recoge casos en que la escena está compuesta por algún elemento desagradable, que centra la atención que se presta al vídeo.

74) Gran despliegue de esfuerzo. El relato del vídeo refleja una escena de composición compleja, cuya construcción implica un considerable esfuerzo.

75) La acción sobreviene a la grabación. El gancho de contenido viene representado por la circunstancia o estado en que una cámara se encuentra grabando y, dada esa situación, sucede la acción. Se imprime realismo y se acentúa el carácter dramático de los acontecimientos. La muestra apunta a estas claves en relatos amateur, de captación de la realidad.

76) Escena de peligro real. El realismo constituye un gancho por sí mismo, pero cuando retrata una escena de peligro en que el espectador puede comprobar la sensación de riesgo en el agente, se consolida como clave específica del contenido.

\section{- Varios:}

77) Captación en vivo. Se corresponde con la grabación de un hecho en el instante en que sucede. Se trata de un parámetro inherente a la mayor parte de grabaciones registradas, pero se ha considerado preciso registrarlo de forma aislada.

78) Temática de actualidad. Según se desprende de la muestra, constituye una clave del atractivo del contenido. 
79) Reclamo sexual. El sexo constituye un reclamo efectivo en multitud de medios y géneros comunicativos. La muestra recoge vídeos cuyo gancho es exclusivamente sexual.

80) Violencia. Como el sexo, la violencia está presente en multitud de contenidos y concentra el atractivo de algunos ejemplos analizados.

81) Autosuperación. La condición de imposibilidad superada por el protagonista mediante un esfuerzo constituye un concepto de notable atractivo, con tendencia a la interpretación empática por parte del espectador.

82) Récord. Se denomina así a la clave del relato que recoge una marca máxima (o mínima) en una actividad. En la muestra, esta marca no ha de estar oficialmente contrastada.

83) Canción. De la muestra se desprende que, en algunos casos, la canción ha desempeñado el gancho de contenido.

84) Hit musical. La experiencia con la muestra refleja que un éxito musical consolidado inserto en el relato puede concentrar la atracción al mismo.

85) Hit musical con coreografía. Si el éxito musical es acompañado de un baile o coreografía, se intensifica la consistencia de dicha clave como gancho de contenido. Canción (no hit) con coreografía. La atracción de una puesta en escena coreográfica es tal que a veces afecta a danzas no asociadas a un éxito musical.

86) Parodia / Versión (impropia y con habilidad preferentemente) de cine o musical. La parodia de un contenido u obra reconocible constituye una atracción altamente frecuente en la muestra. Este gancho está basado en la falta de propiedad entre los elementos de la parodia, teniendo en cuenta el conocimiento y significado de los elementos de su referente.

87) Versión regional. La parodia puede resultar igualmente atractiva si se construye teniendo en cuenta un modelo sociogeográfico y cultural concreto.

88) Denuncia social. El registro de una realidad polémica con carácter de denuncia adquiere valor de gancho en función del relato en que se inscribe.

89) Materia de calado internacional. Los asuntos de importancia global, conocidos y tratados mundialmente conllevan una atención afianzada.

90) Drama real / Suicidio. El respaldo realista a un hecho le confiere matiz de clave, pero cuando ese hecho combina morbo y drama con otros parámetros de su protagonista supone un gancho de contenido. 
91) Objeto anecdótico / Nunca visto. El conocimiento de un objeto nuevo, nunca visto o no inventado, constituye un gancho de contenido.

92) Grupo social reconocible. Los aspectos reconocibles de la sociedad pueden desempeñar un rol de clave del relato, según lo extraído del estudio de la muestra.

\section{- Gancho auxiliar de contenido:}

Las claves que se enumeran a continuación conforman aspectos auxiliares que refuerzan la atracción del vídeo y que, -pese a considerarse secundarios- debido a la frecuencia con que se repiten en la muestra analizada, es necesario reflejar:

93) De agradable visionado. La composición armoniosa en términos generales, o una conveniente ecuación de los elementos estéticos de la pieza pueden desempeñar una clave complementaria de contenido.

94) Frase repetitiva. La facilidad para el recuerdo y la imitación, unido a otros elementos que, por lo general, atañen al personaje que la profiere.

95) Humor. Se establece como resultado el registro del humor como tono, tendencia o finalidad del contenido del vídeo en términos de gancho único o complementario.

96) Fenómeno fan.

97) Título. El título de un vídeo constituye un elemento de considerable injerencia en los patrones de comportamiento viral, y su acertada elección puede significar un gancho auxiliar de contenido.

98) Referencia a vídeo viral o a hit musical. Cuando se emplea la referencia a un contenido de consolidado comportamiento viral para construir otro, éste lleva asignado un valor añadido y, en ocasiones, resulta el gancho de atracción principal de su contenido.

99) Ante expectación. Que la acción conlleve expectación asociada da al relato un matiz de publicidad que acentúa la gravedad de una eventual sensación de ridículo, así como la expresión emocional o el carácter impropio de alguno de los elementos del contenido.

\section{CONCLUSIONES}

Los contenidos que experimentan un proceso de contagio generan una enorme atracción en torno a los motivos que justifican su éxito (Broxton et al., 2013). El estudio presentado focaliza el fenómeno de expansión de contenidos en los aspectos más 
atractivos del contenido, obteniendo como resultado 99 claves dramáticas también denominadas ganchos, presentes en la muestra de vídeos virales citada. Según el estudio realizado, la inclusión de dichos parámetros dramáticos en una obra videográfica contribuye de forma efectiva a su aceptación y propagación por parte del público usuario de la red. La relación de parámetros que se recogen como claves narrativas del contenido viral constituyen características presentes en todos los contenidos de éxito. Este hallazgo resulta de gran importancia para la investigación de los gustos de la audiencia en Internet pero también para el estudio del personaje, la narrativa y el contenido audiovisual en los medios nuevos y tradicionales.

\section{BIBLIOGRAFÍA}

BROXTON, T., INTERIAN, Y., VAVER, J. y WATTENHOFFER, M. (2013): “Catching a viral video", Journal of Intelligent Information Systems, vol. 40, no 2, pp. 241-259. DOI: http://dx.doi.org/10.1007/s10844-011-0191-2

BURGESS, J. (2008). "All Your Chocolate Rain Are Belong to Us? Viral Video, YouTube and the Dynamics of Participatory Culture", en VV.AA.: Video Vortex Reader: Responses to YouTube. Amsterdam: Institute of Network Cultures, pp. 101-109. Disponible en https://goo.gl/TZ3mW8. Consultado el 7 octubre de 2013.

BURGESS, J. y GREEN, J. (2009): YouTube video online and participatory culture. Cambridge: Polity.

PÉREZ, J. (2011): “La interacción entre internet y los medios convencionales en la creación de fenómenos mediáticos: Jesse Heiman goes viral”, Razón y Palabra, № 76. Disponible en https://goo.gl/co9usG. Consultado el 7 de febrero de 2013.

RUISMÄKI, H. y RUOKONEN, I. (2013): "How to dance Harlem Shake in Finland. Creating a Video Project", The European Journal of Social \& Behavioural Sciences, vol. VII, no 4, pp. 1.244-1.251. DOI: http://dx.doi.org/10.15405/ejsbs.104

SNICKARS, P. y VONDERAU, P. (eds.) (2009): The YouTube reader. Stockholm: National Library of Sweden.

TEIXEIRA, T. (2012): "The new science of viral ads", Harvard Business Review. Disponible en https://goo.gl/8Ze0xU. Consultado el 20 de marzo de 2013.

TEIXEIRA, T. (2014): "Research Shows Which TV Ads Are Likely to Make Multitaskers Buy", Harvard Business Review. Disponible en https://goo.gl/fxCwKY. Consultado el 20 enero 2015.

VOLTZ, S. y GROBE, F. (2013): The Viral Manifesto. USA: McGraw Hill. 
Laura PICAZO SÁNCHEZ es doctora en Ciencias de la Información por la Universidad Complutense de Madrid. Especialista en el fenómeno viral de YouTube y en las claves del contagio, es experta en contenidos audiovisuales de éxito. Ha realizado, además, un estudio predoctoral sobre el vídeo casero. Su trayectoria profesional abarca el sector de la producción cinematográfica, la docencia presencial y online y la investigación científica. Su objetivo actual es la formación de adolescentes en el consumo y creación de contenidos en la red. Correo electrónico: laura.picazo.sanchez@gmail.com. 